\title{
Aaron Temkin Beck
}

\author{
Ayesha Sultana \\ Post Graduate, Dept. of Psychiatry, Prathima Institute of Medical Sciences, Karimnagar, Telangana, India
}

*Corresponding Author: Ayesha Sultana

Email: drayesha.shrink@gmail.com

\begin{abstract}
Aaron Temkin Beck (born July 18, 1921) is an American psychiatrist and a professor emeritus in the Department of Psychiatry at the University of Pennsylvania. Beck is noted for his research in psychotherapy, psychopathology, suicide, and psychometrics. He is regarded as the father of Cognitive Therapy. His theories are widely used in the treatment of clinical depression. Beck developed self-report measures of depression and anxiety, notably the Beck Depression Inventory (BDI) which became one of the most widely used instruments for measuring depression severity. He has published more than 600 professional journal articles, and authored or co-authored 25 books.

Beck has been named one of the "Americans in history who shaped the face of American Psychiatry" and one of the "five most influential psychotherapists of all time" by The American Psychologist in July 1989. He is currently the President Emeritus of the Beck Institute for Cognitive Behavior Therapy set up by him and his daughter, psychologist Judith S. Beck and the Honorary President of the Academy of Cognitive Therapy, which certifies qualified cognitive therapists.
\end{abstract}

Keywords: Aaron T Beck, Cognitive therapy, Beck depression inventory.

\section{Introduction}

Dr. Beck was born in Providence, Rhode Island, United States. He was the youngest of the five children. Both of his parents were Russian Jewish immigrants to the United States. Two of Beck's siblings had died before his birth, an elder brother in childhood and elder sister in the influenza pandemic of 1919. As a result of these tragedies, Beck's mother was chronically depressed for several years and became overprotective of her youngest son. At 7 years of age, he broke his arm that kept him in the hospital long enough that he missed his promotion into second grade. He recalled later that he came to feel "stupid" and "dumb". With the help of his determination, Beck caught up with his studies and was promoted a year ahead of his classmates. He regarded his success as a psychological turning point. He graduated as the head of his class from Hope High School. ${ }^{1}$

Beck entered Brown University in the fall of 1938 . He majored in Political Science and English Literature. He also served as associate editor to the campus newspaper, the Brown Daily Herald. He graduated from the university magna cum laude in 1942. Beck won a number of honors and awards as an undergraduate, including the Francis Wayland Scholarship, the Gaston prize for Oratory, and the election to Brown's chapter of Phi Beta Kappa. ${ }^{2}$

Beck went to medical school at Yale University, after graduating from Brown University. He completed his degree in $1946 .^{2}$ After receiving his MD; he served a rotating internship followed by a residency in pathology at Rhode Island Hospital. He then decided to specialize in neurology. While he was completing a required rotation in psychiatry during his residency at the Cushing Veterans Administration Hospital in Framingham, Massachusetts, he became absorbed in psychoanalysis. ${ }^{1}$

After completing his medical internships and residencies from 1946 to 1950, Beck became Fellow in psychiatry at the Austen Riggs Center, a private mental hospital in the mountains of Stockbridge, Massachusetts, until 1952. Beck then completed military service as assistant chief of neuropsychiatry at Valley Forge Army Hospital in the United States Military. ${ }^{3}$

Beck was married in 1950 to Phyllis W. Beck, who was the first woman judge on the appellate court of the Commonwealth of Pennsylvania. They have four adult children: Roy,

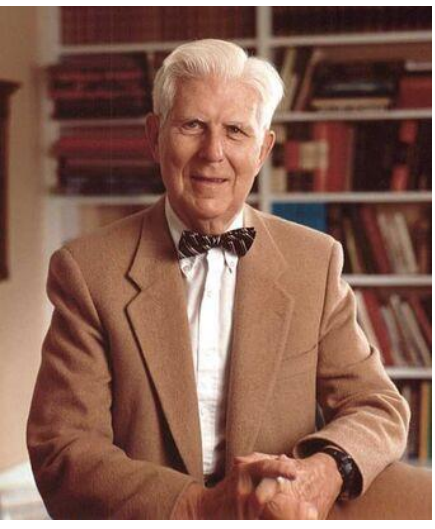
Judy, Dan, and Alice. ${ }^{1}$ Beck's daughter Judith is a prominent cognitive behavioral therapy (CBT) educator and clinician, who wrote the basic text in the field. She is President of the non-profit Beck Institute. ${ }^{2}$

Beck received his board certification in psychiatry in 1953, joined the Department of Psychiatry of the University of Pennsylvania in 1954, and completed his graduate training in psychoanalysis at the Philadelphia Psychoanalytic Institute in 1958. In 1961, he developed Beck Depression Inventory. He is the only person to have been given awards from both the American Psychiatric Association and American Psychological Association. ${ }^{1} \mathrm{He}$ remained at Penn until he retired from active teaching in 1992, when he was appointed University Professor Emeritus of Psychiatry. ${ }^{2}$

\section{Contributions of Dr. Aaron T Beck}

Working with depressed patients, Dr. Beck found that they experienced streams of negative thoughts that seemed to pop up spontaneously. He termed these cognitions "automatic thoughts". People with depression will tend to quickly overlook their positive attributes and disqualify their accomplishments as being minor or meaningless. They may also misinterpret the care, good will, and concern of 
others as being based on pity or susceptible to being lost easily if those others knew the "real person" and this fuels further feelings of guilt.

Beck's cognitive triad, also known as the negative triad, ${ }^{4}$ is a cognitive- therapeutic view of the three key elements of a person's belief system present in depression. Beck proposed this triad in $1976 . .^{5}$ The triad forms part of his cognitive theory of depression and the concept is used as part of CBT, particularly in Beck's "Treatment of Negative Automatic Thoughts" (TNAT) approach.

The triad involves "automatic, spontaneous and seemingly uncontrollable negative thoughts" about:

1. The self

2. The world or environment

3. The future

Beck began helping patients identify and evaluate these thoughts and found that by doing so, patients were able to think more realistically, which led them to feel better emotionally and behave more functionally. He developed key ideas in Cognitive Behavior Therapy, explaining that different disorders were associated with different types of distorted thinking. Distorted thinking has a negative effect on a person's behavior no matter what type of disorder they had, he found. Beck explained that successful interventions will educate a person to understand and become aware of their distorted thinking, and how to challenge its effects. He discovered that frequent negative automatic thoughts reveal a person's core beliefs. ${ }^{6}$

Beck proposed "the generic cognitive model". He condensed the formulation to "generic quartet". This consists of the stimulus situation, the dysfunctional belief, symptoms of disorder and excessive focus on symptoms, belief, or activating stimulus. Each of the components of the quartet interact with one another so that changes in one, impact the others. He and his colleagues have researched the efficacy of this form of psychotherapy in treating a wide variety of disorders including depression, bipolar disorder, eating disorders, drug abuse, anxiety disorders, personality disorders, and many other medical conditions with psychological components. $^{7}$

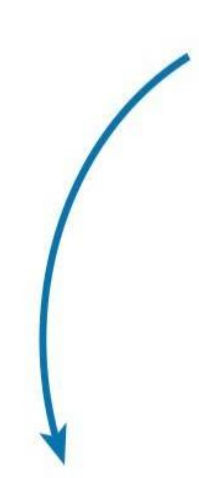

\section{Situation}

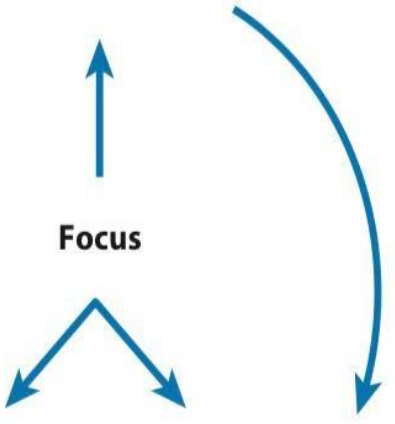

Behavior

Belief
Beck also believed that a depressed person will, often from childhood experiences, hold a negative self-schema. This schema may originate from negative early experiences, such as criticism, abuse or bullying. Beck suggests that people with negative self-schemata are liable to interpret information presented to them in a negative manner, leading to the cognitive distortions. This explanatory style involves blaming oneself for negative events outside of their control or the behavior of others (personalization), believing that such events will continue forever and letting these events significantly affect their emotional wellbeing. ${ }^{5}$

\section{Positions Held:2}

1. Beck is the founder and President Emeritus of the nonprofit Beck Institute for Cognitive Therapy and Research.

2. He is the director of the Psychopathology Research Center (PRC), which is the parent organization of the Center for the Treatment and Prevention of Suicide.

3. In 1986, he was a visiting scientist at Oxford University.

4. He has been professor emeritus at Penn since 1992.

5. He is also an adjunct professor at both Temple University and University of Medicine and Dentistry of New Jersey.

\section{Questionnaires}

1. Beck Depression Inventory (BDI).

2. Beck Hopelessness Scale.

3. Beck Scale for Suicidal Ideation (BSS).

4. Beck Anxiety Inventory (BAI).

5. Beck Youth Inventories.

6. Clark-Beck Obsessive-Compulsive Inventory(CBOCI)

7. BDI-Fast Screen for Medical Patients.

8. Beck collaborated with psychologist Maria Kovacs in the development of the Children's Depression Inventory.

\section{Awards Received:2}

1. The 7th Annual Heinz Award in the Human Condition

2. The 2004 University of Louisville Grawemeyer Award for Psychology.

3. The 2006 Lasker-DeBakey Clinical Medical Research Award.

4. The 2010 Bell of Hope Award.

5. The 2010 Sigmund Freud Award.

6. The 2010 Scholarship and Research Award.

7. The 2011 Edward J. Sachar Award.

8. The 2011 Prince Mahidol Award in Medicine.

9. The 2013 Kennedy Community Mental Health Award.

\section{Books by Dr. Aaron Beck:2}

1. The Diagnosis and Management of Depression (1967).

2. Depression: Causes and Treatment (1972).

3. Cognitive Therapy and the Emotional Disorders(1975)

4. Cognitive Therapy of Depression (with John Rush, Brian Shaw, \& Gary Emery, 1979).

5. Cognitive Therapy in Clinical Practice: An Illustrative 
Casebook (with Jan Scott \& Mark Williams, 1989).

6. The Integrative Power of Cognitive Therapy(with Brad Alfred, 1998).

7. Prisoners of Hate: The Cognitive Basis of Anger, Hostility, and Violence (1999).

8. Scientific Foundations of Cognitive Theory and Therapy of Depression (with David Clark,1999)

9. Cognitive Therapy of Personality Disorders(with Arthur Freeman, 2003).

10. Cognitive Therapy with Inpatients: Developing A Cognitive Milieu (with Jesse Wright, Michael Thase, \& John Ludgate, 2003).

11. Cognitive Therapy With Chronic Pain Patients(with Carrie Winterowd \& Daniel Gruener, 2003).

12. Anxiety Disorders and Phobias: A Cognitive Perspective (with Gary Emergy \& Ruth Greenberg, 2005).

13. Schizophrenia: Cognitive Theory, Research, and Therapy (with Neil Rector, Neal Stolar, \& Paul Grant, 2008).

14. Cognitive Therapy of Anxiety Disorders: Science and Practice (with David Clark, 2010).

\section{Sources of Funding}

Nil.

\section{Conflict of Interest}

Nil.

\section{References}

1. Beck. Biography [Internet]. University Park (PA): The Pennsylvania State University; c2019 [cited 2020 Nov 21]. Available from : https://pabook.libraries.psu.edu/beck aaron temki

2. Beck AT. Beck Institute for Cognitive Behavior Therapy https://beckinstitute.org/team/dr-aaron-t-beck/ (accessed 21 November, 2020).

3. Yavuz F, Türkçapar H. Aaron Temkin Beck (born July 18, 1921-) Biography. Available from: https://www.bibliomed.org/mnsfulltext/77/771342719698.pdf?1612170094.

4. Gross R. Psychology: The Science of Mind and Behaviour 7th Edition. Hodder Education. 2015; pp. 796,797

5. Beck AT, Rush AJ, Shaw BF. Cognitive Therapy of Depression. Guilford Press. https://www.guilford.com/books/Cognitive-Therapy-ofDepression/Beck-Rush-Shaw-Emery/9780898629194 (accessed 21 November, 2020).

6. Beck A. The Past and Future of Cognitive Therapy. $J$ Psychother Pract Res. 1997;6276-284.

7. Beck AT, Haigh EAP. Advances in cognitive theory and therapy: the generic cognitive model. Ann Rev Clin Psychol. 2014;10(1):24.

How to cite this article: Sultana A. Aaron Temkin Beck. Telangana J Psychiatry. 2020;6(2):189-191. 